\title{
Article \\ Progressive Comparison of Density Assessment of Alveolar Bone Graft in Patients with Unilateral and Bilateral Cleft
}

\author{
Pin-Ru Chen ${ }^{1}$, Yu-Ching Lin ${ }^{2}\left(\mathbb{D}\right.$, Betty Chien-Jung Pai ${ }^{3}$, Hsiao-Jung Tseng ${ }^{4}$, Lun-Jou Lo ${ }^{1}$ (D) \\ and Pang-Yun Chou ${ }^{1, *(1)}$
}

1 Craniofacial Research Center, Department of Plastic and Reconstructive Surgery, Chang Gung Memorial Hospital, Chang Gung University, Taoyuan 33302, Taiwan; pinru99@gmail.com (P.-R.C.); lunjoulo@cgmh.org.tw (L.-J.L.)

2 Department of Medical Imaging and Intervention, Chang Gung Memorial Hospital at Keelung, College of Medicine, Chang Gung University, Taoyuan 33302, Taiwan; yuching1221@gmail.com

3 Craniofacial Research Center, Department of Craniofacial Orthodontics, Chang Gung Memorial Hospital, Chang Gung University, Taoyuan 33302, Taiwan; pai0072@cgmh.org.tw

4 Clinical Trial Center, Biostatistics Unit, Chang Gung Memorial Hospital, Taoyuan 33302, Taiwan; allebjht@gmail.com

* Correspondence: chou.asapulu@gmail.com; Tel.: +886-3-328-1200 (ext. 3354)

Citation: Chen, P.-R.; Lin, Y.-C.; Pai, B.C.-J.; Tseng, H.-J.; Lo, L.-J.; Chou, P.-Y. Progressive Comparison of Density Assessment of Alveolar Bone Graft in Patients with Unilateral and Bilateral Cleft. J. Clin. Med. 2021, 10, 5143. https://doi.org/10.3390/ jcm10215143

Academic Editor: Izumi Asahina

Received: 30 September 2021

Accepted: 29 October 2021

Published: 1 November 2021

Publisher's Note: MDPI stays neutral with regard to jurisdictional claims in published maps and institutional affiliations.

Copyright: (c) 2021 by the authors. Licensee MDPI, Basel, Switzerland. This article is an open access article distributed under the terms and conditions of the Creative Commons Attribution (CC BY) license (https:// creativecommons.org/licenses/by/ $4.0 /)$.

\begin{abstract}
Background: Continuing to observe the grafted bone mineral density (BMD) is essential to ensure the success of alveolar bone grafting (ABG) in patients with cleft lip and palate. This study elaborates on three methods that can be used to evaluate the progressive BMD. (2) Methods: Forty patients with unilateral or bilateral clefts receiving ABG were enrolled. Cone beam computed tomography (CBCT) scans were taken at 6 months (T1) and 2 years (T2) postoperatively. In CBCT, measurements were obtained on three different planes using the circle located $1 \mathrm{~mm}$ from the adjacent teeth (Method A), the largest circle within the defect (Method B), or the central circle with a diameter of $2 \mathrm{~mm}$ (Method C). The BMD was the average density of the three planes and was adjusted by pogonion density. Bland-Altman plots were used to evaluate the agreement of each method. Interrater reliability was confirmed by the intraclass correlation coefficient (ICC). (3) Results: For Method $\mathrm{A}, \mathrm{B}$, and $\mathrm{C}$, the mean-adjusted $\mathrm{BMD}\left(\mathrm{BMD} /\right.$ pogonion density, $\mathrm{BMD}_{\mathrm{a}}$ ) was $17.44 \%, 17.88 \%$, and $17.69 \%$, respectively, at T1 $(p=0.495)$, and $22.51 \%, 22.87 \%$, and $22.74 \%$, respectively, at T2 $(p=0.690)$; the density enhancement rates were $40.54 \%, 38.92 \%$, and $43.15 \%(p=0.382)$. Significant differences between the $\mathrm{BMD}_{\mathrm{a}}$ at T1 and T2 were observed $(p<0.001,<0.001$, and 0.001 , for Method A, B, and C, respectively). The volume of the grafted tissue remained stable during $\mathrm{T} 1$ and $\mathrm{T} 2$, and no significant correlation between density enhancement rate and volume loss was observed. (4) Conclusions: A significant increase in the BMD of grafted tissue was observed in the 2-year postoperative follow-up. The three methods for measuring $\mathrm{BMD}_{\mathrm{a}}$ via $\mathrm{CBCT}$ can be applied in post-ABG evaluations.
\end{abstract}

Keywords: alveolar bone grafting; alveolar cleft; bone mineral density; density enhancement rate; cone beam computed tomography (CBCT)

\section{Introduction}

Secondary alveolar bone grafting $(\mathrm{ABG})$ is a standard and necessary procedure for treating patients with cleft lip and palate (CLP) [1,2]. ABG serves to stabilize the continuity of the maxillary arch, provide support for tooth eruption, provide bony support for adjacent teeth to ensure long-term periodontal health, support the alar base, and improve speech. If $\mathrm{ABG}$ is not performed properly, midface retrusion may be observed when the bone matures [3-5].

Traditionally, imaging assessment of ABG outcomes is conducted using two-dimensional radiography and scales, such as the Bergland scale; however, computed tomography (CT)based studies have indicated that conventional radiographs tend to overestimate bone 
growth $[3,6,7]$. Cone beam CT (CBCT) is characterized by a low radiation dose and cost effectiveness; it can be performed using high-quality three-dimensional (3D) image acquisition and reconstruction parameters, including the characteristics of the maxillary alveolar anatomical boundaries; therefore, researchers are increasingly using $\mathrm{CBCT}$ for diagnostic and therapeutic evaluations of ABG [8-10]. Because the success of a dental implantation is affected by bone quality, assessing bone height and bone mineral density (BMD) is essential before a dental implantation is performed [11]. Many studies have examined bone height; however, few have proposed methods for assessing the BMD of grafted tissue and tracking the progression of BMD.

A new ABG method for Scarpa's fascia grafts [2] and obtained CBCT images of children with CLP were adopted to prepare for postoperative follow-up. In the present study, we used the aforementioned CBCT images to design a new and easier method for evaluating the BMD of grafted tissue. We proposed three methods for measuring BMD and hypothesized that the three methods would yield similar results. In addition, we compared the density of grafted tissues with adjacent bony tissue in the growth stages and assessed the density enhancement rate in the first 2 years after surgery.

\section{Patients and Methods}

\subsection{Patient Information and Data Collection}

Patients who had nonsyndromic unilateral or bilateral cleft lip and alveolus with or without cleft palate and received ABG at our center between 2016 and 2018 were enrolled. All patients underwent at least 2 CBCT scans after operation. Postoperative image acquisition was performed at two time points, namely 6 months (T1) and 2 years (T2) after ABG. The ABG procedures for all patients were performed by the same senior surgeon as per the protocol of our center, which comprises an iliac cancellous bone graft and the sealing of Scarpa's fascia to the defect before the bone graft is packed $[2,12]$. Patients who had syndromic cleft alveolus, who underwent two-stage ABG (performed for bilateral cases), or who exhibited failed grafted tissue were excluded. In total, 40 patients were enrolled in the present study. The demographic and clinical variables for ABG were retrospectively collected through a review of medical charts. All CBCT images were obtained using an i-CAT CBCT scanner (Imaging Sciences International, Hatfield, PA, USA); the parameters for the images are as follows: $120 \mathrm{kVp}$, voxel size of $0.4 \times 0.4 \times 0.4 \mathrm{~mm}^{3}$, $40 \mathrm{~s}$ scan time, and $22 \times 16 \mathrm{~cm}$ field of view.

\subsection{BMD Measurement and Volumetric Analysis}

The Picture Archiving and Communication System (PACS) was applied for BMD analysis. Three methods (A, B, and C), which differed by the size of the selected area, were designed to measure Hounsfield units (HUs). For all methods, we first identified the most superior and inferior planes transecting the grafted tissue on the coronal view image; subsequently, the middle plane of the grafted tissue was identified (Figure 1). For the selected plane, the distance between two teeth had to be larger than $2.5 \mathrm{~mm}$ in diameter; this was required for all three methods. On each plane, the selected circular area is defined as being located at the midpoint of the line between the centers of the two adjacent teeth. The HU of the selected area could be obtained using PACS.

For Method A, the circular zone located $1 \mathrm{~mm}$ from the adjacent teeth was selected. For Method B, the largest circular zone that exactly transected the two adjacent teeth or was tangent to the surrounding cortical bone was selected. For Method C, a circle was drawn with a diameter of $2 \mathrm{~mm}$. Furthermore, the largest circular zone in the pogonion bone marrow was selected to obtain its $\mathrm{HU}$ at $\mathrm{T} 1$ and $\mathrm{T} 2$; this was the reference for calibration (Figures 1 and 2). HU was the reference for BMD and represented the average density of the three planes. We defined the adjusted $\mathrm{BMD}\left(\mathrm{BMD}_{\mathrm{a}}, \%\right)$ using the following formula: 


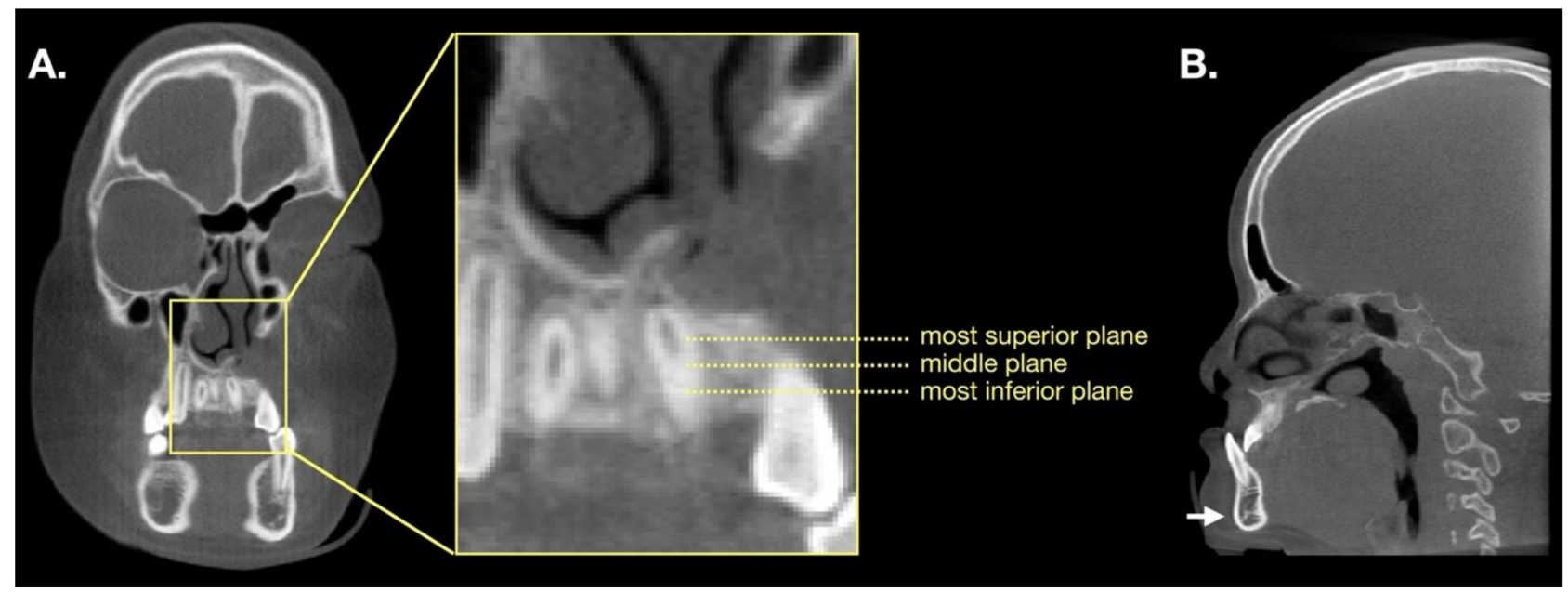

Figure 1. Identification of the selected planes. (A) Identified the most superior and inferior planes transecting the grafted tissue on the coronal view image; subsequently, the middle plane of the grafted tissue was identified. (B) The pogonion was identified on the sagittal view.

A.
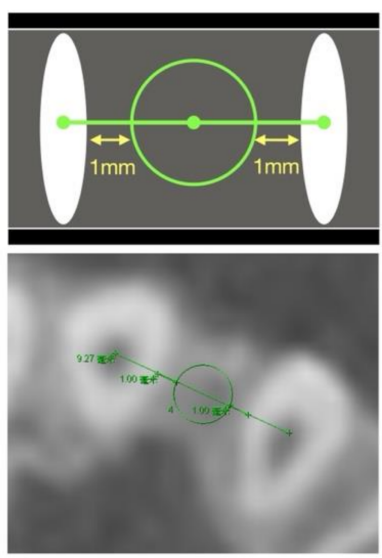

C.
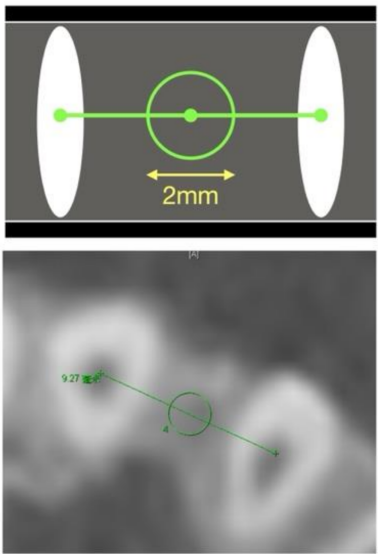

B1.
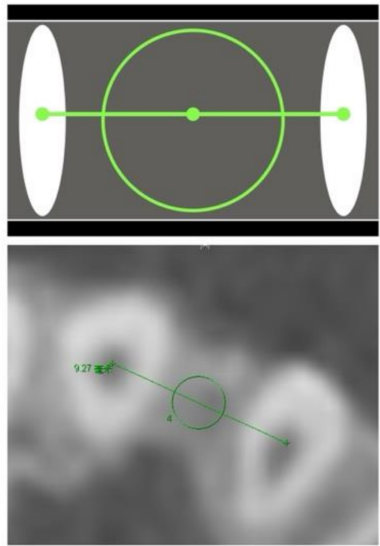

D.

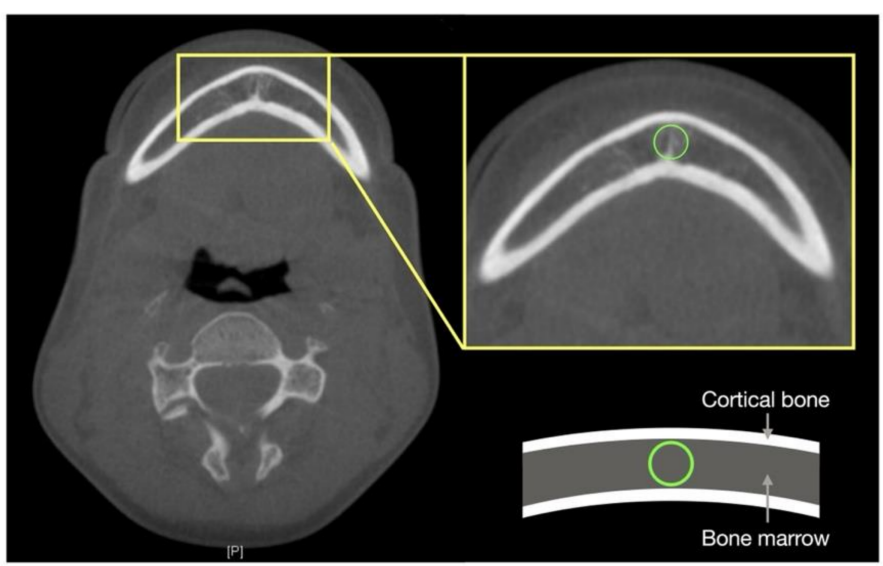

Figure 2. Axial image of grafted area with schemes. (A) For Method A, a circle located $1 \mathrm{~mm}$ from the adjacent teeth is sketched. For Method B, the largest circular area of grafted tissue is sketched. Two possible conditions apply for Method B. (B1) If the distance between two adjacent teeth is greater than the thickness of the alveolar defect, a circle tangent to surrounding cortical bone density is drawn. (B2) If the distance between two adjacent teeth is less than the thickness of the alveolar defect, a circle transecting the two adjacent teeth is selected. (C) For Method C, a central circle with a diameter of $2 \mathrm{~mm}$ is drawn. Note that (A), (B1), and (C) are images of the same patient. (D) The largest circular zone within the pogonion bone marrow is used to obtain the pogonion density for calibration. 


$$
\operatorname{BMD}_{\mathrm{a}}(\%)=\frac{\mathrm{HU}_{\text {selected zone }}}{\mathrm{HU}_{\text {pogonion }}} \times 100
$$

The density enhancement rate (\%) was calculated using the following formula:

$$
\text { Density enhancing rate }(\%)=\frac{\mathrm{BMD}_{\mathrm{aT} 2}-\mathrm{BMD}_{\mathrm{aT} 1}}{\mathrm{BMD}_{\mathrm{aT} 1}} \times 100
$$

where $\mathrm{BMD}_{\mathrm{aT2}}$ is $\mathrm{BMD}_{\mathrm{a}}$ measured at $\mathrm{T} 2$ and $\mathrm{BMD}_{\mathrm{aT1}}$ is the $\mathrm{BMD}_{\mathrm{a}}$ at $\mathrm{T} 1$.

All the BMD and pogonion density data were measured by one examiner and repeated twice on different dates that were separated by a 3-month interval; the second round of measurements was conducted without reference to the first-round measurements. The average of the six sets of data (two measurements for each of the three planes) was used for the final statistical analysis.

As for the volumetric analysis, segmentation of the grafted tissue was performed using ITK-SNAP 3.6.0 open-source software [13]. The grafted tissue was confirmed by axial, coronal, and sagittal views at the same time (Figure 3), and the volume of the segmented area could be displayed.

A.

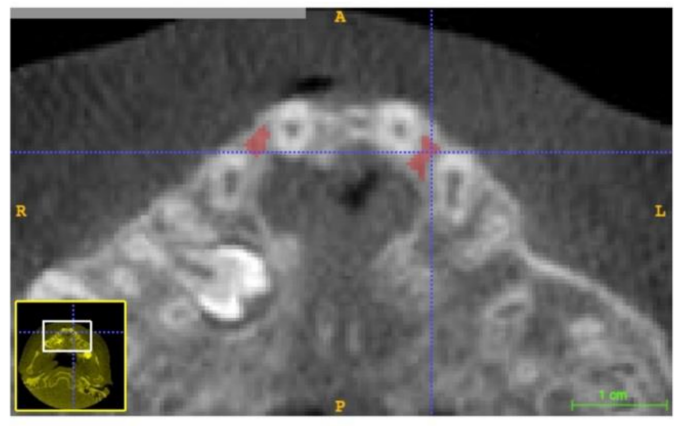

C.

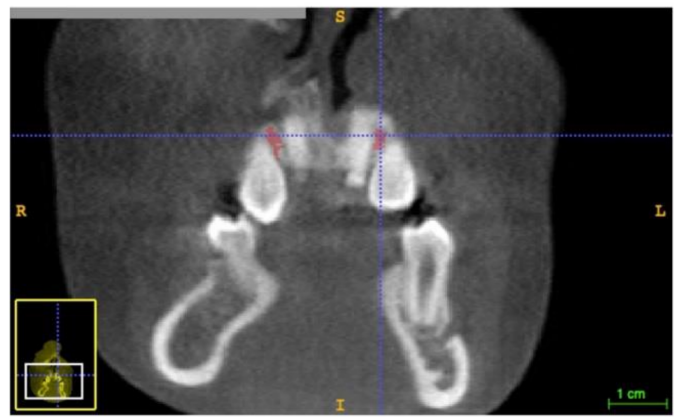

B.

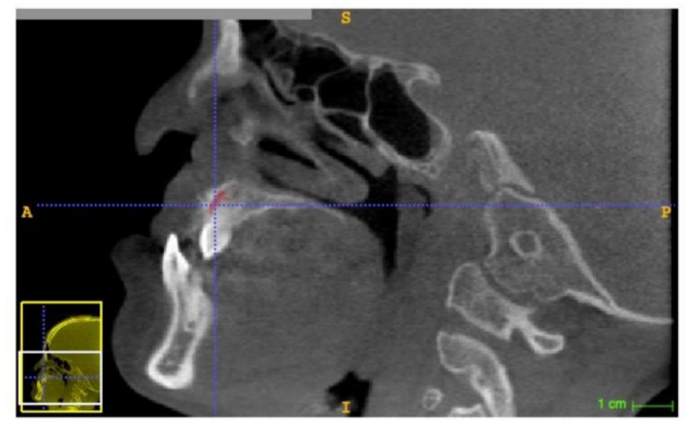

D.

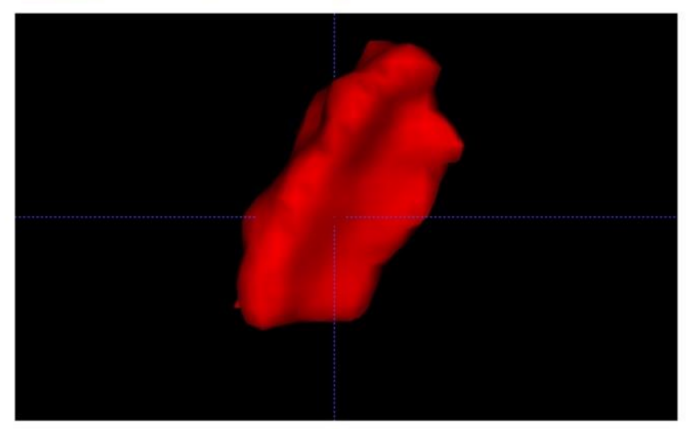

Figure 3. Volumetric analysis of the grafted tissue using ITK-SNAP 3.6.0 open-source software. (A) The axial view of the grafted tissue. (B) The sagittal view of the grafted tissue. (C) The coronal view of the grafted tissue. (D) The 3D display of the grafted tissue after segmentation.

\subsection{Statistical Analysis}

In the descriptive analysis, continuous variables were summarized by means \pm standard deviations, with an independent $t$-test used to compare the means between two groups; a chi-squared test or Fisher's exact test was used for categorical data. Furthermore, we performed analysis of variance (ANOVA) with repeated measurements to compare the differences between the three methods with respect to $\mathrm{BMD}_{\mathrm{a}}$ measurements and density enhancement rates; a Friedman test was used for the bilateral group due to a small sample size. To compare the differences in $\mathrm{BMD}_{\mathrm{a}}$ at $\mathrm{T} 1$ and $\mathrm{T} 2$, we performed a paired $t$-test or a Wilcoxon signed-rank test for the bilateral group. The correlation between volume loss and density enhancement rate between T1 and T2 was performed using Spearman's correlation. Bland-Altman plots were used to evaluate the agreement of each method. 
Intraclass correlation coefficients (ICCs) were calculated as the measure of the intrarater reliability for the three methods. All data were analyzed using SPSS 24.0 (SPSS, Chicago, IL, USA). A $p$-value of less than 0.05 was considered statistically significant by two-tailed tests.

\section{Results}

\subsection{Subject Characteristics}

The study was approved by the relevant institutional review board. In total, 40 patients, who had an average age of $9.45 \pm 1.61$ years when they received ABG, were enrolled. Among the patients, $60 \%(n=24)$ were male and $82.5 \%(n=33)$ had unilateral alveolar cleft. The first (T1) and second (T2) follow-up CBCTs were taken at $6.67 \pm 0.82$ months and $24.04 \pm 5.15$ months after ABG (Table 1).

Table 1. Patient demographics and follow-up length.

\begin{tabular}{|c|c|c|c|c|}
\hline Variables & All $(n=40)$ & Unilateral $(n=33)$ & Bilateral $(n=7)$ & $p$-Value \\
\hline Age at ABG (year) & $9.45 \pm 1.61$ & $9.36 \pm 1.69$ & $9.86 \pm 1.12$ & 0.467 \\
\hline Men $(n(\%))$ & $24(60.0 \%)$ & $19(57.6 \%)$ & $5(71.4 \%)$ & 0.681 \\
\hline \multicolumn{5}{|l|}{ ABG method } \\
\hline Scarpa's fascia $(n(\%))$ & $40(100 \%)$ & $33(100 \%)$ & $7(100 \%)$ & - \\
\hline Bone graft from iliac crest $(n(\%))$ & $40(100 \%)$ & $33(100 \%)$ & $7(100 \%)$ & - \\
\hline Graft volume $(\mathrm{mL})[2]$ & - & $2.0 \pm 0.6$ & $3.8 \pm 1.0$ & - \\
\hline \multicolumn{5}{|l|}{ CBCT follow-up post-surgery } \\
\hline First follow-up (month) & $6.67 \pm 0.82$ & $6.60 \pm 0.79$ & $6.97 \pm 0.93$ & 0.284 \\
\hline Second follow-up (month) & $24.04 \pm 5.15$ & $23.65 \pm 4.65$ & $25.86 \pm 7.23$ & 0.465 \\
\hline
\end{tabular}

Data are presented as means \pm standard deviations or $n(\%)$ and stratified by unilateral or bilateral alveolar cleft with an independent $t$-test to compare means between two groups. Categorical data are examined using the chi-squared test or Fisher's exact test.

\subsection{Adjusted BMD and Density Enhancement Rate}

The mean $\mathrm{BMD}_{\mathrm{a}}$ of the grafted tissue at $\mathrm{T} 1$ were $99.70 \% \pm 49.18 \%, 101.90 \% \pm 52.05 \%$, and $101.78 \% \pm 59.74 \%$ when measured by Method A, B, and C, respectively; at T2, the values were $121.45 \% \pm 53.98 \%, 123.55 \% \pm 55.52 \%$, and $122.74 \% \pm 58.81 \%$ for Method $\mathrm{A}$, $\mathrm{B}$, and $\mathrm{C}$, respectively (Figure 4 and Table 2). When comparing the progressing density between $\mathrm{T} 1$ and $\mathrm{T} 2$, significant differences in $\mathrm{BMD}_{\mathrm{a}}$ were observed for the three measurement methods ( $p=0.004,0.004$, and 0.009 for Method A, B, and C, respectively). The mean density enhancement rates were $35.85 \% \pm 51.99 \%, 35.61 \% \pm 51.75 \%$, and $37.59 \% \pm 56.41 \%$ for Method A, B, and C, respectively. When comparing the differences in measurement values between the three methods, no statistical difference was observed for $\mathrm{BMD}_{\mathrm{a}}(p=0.536$ at $\mathrm{T} 1$ and $p=0.689$ at $\mathrm{T} 2)$ or density enhancement rate $(p=0.681)$.

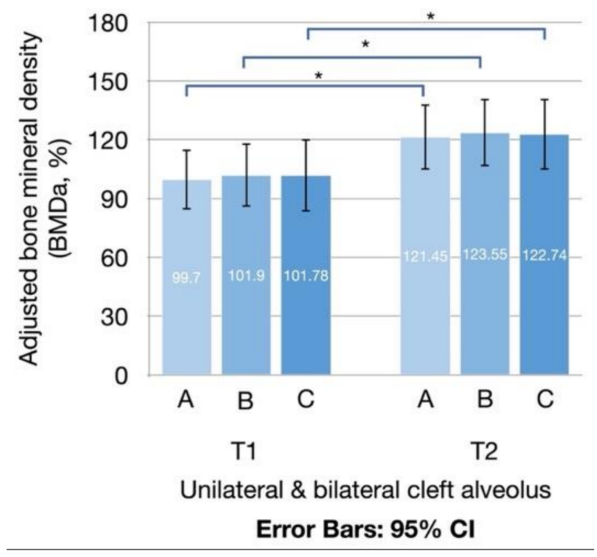

Figure 4. Error bars of adjusted bone mineral density (BMDa) of grafted tissue at T1 and T2. Stars indicate significant differences in $\mathrm{BMD}_{\mathrm{a}}$ between $\mathrm{T} 1$ and $\mathrm{T} 2:{ }^{*}, p<0.05$. 
Table 2. Outcomes of cone beam computed tomography.

\begin{tabular}{|c|c|c|c|c|c|}
\hline Variables & Method & Overall & Unilateral & Bilateral & $p$-Value \\
\hline \multicolumn{6}{|l|}{$\mathrm{BMD}_{\mathrm{T} 1}(\mathrm{HU})$} \\
\hline & A & $293.88 \pm 135.27$ & $292.63 \pm 135.45$ & $299.78 \pm 145.08$ & 0.901 \\
\hline & B & $299.50 \pm 137.54$ & $298.70 \pm 137.77$ & $303.25 \pm 147.39$ & 0.983 \\
\hline & C & $295.84 \pm 150.24$ & $295.79 \pm 150.20$ & $296.08 \pm 162.45$ & 0.996 \\
\hline \multicolumn{6}{|l|}{$\mathrm{BMD}_{\mathrm{T} 2}(\mathrm{HU})$} \\
\hline & $\mathrm{A}$ & $360.90 \pm 175.46$ & $358.34 \pm 184.54$ & $373.01 \pm 135.14$ & 0.844 \\
\hline & B & $366.90 \pm 178.55$ & $366.16 \pm 186.93$ & $370.41 \pm 144.32$ & 0.955 \\
\hline & C & $361.97 \pm 185.96$ & $362.65 \pm 195.78$ & $358.78 \pm 142.62$ & 0.961 \\
\hline \multicolumn{6}{|l|}{$\mathrm{BMD}_{\mathrm{aT} 1}(\%)$} \\
\hline & $\mathrm{A}$ & $99.70 \pm 49.18$ & $100.01 \pm 46.98$ & $98.24 \pm 62.85$ & 0.932 \\
\hline & B & $101.90 \pm 52.05$ & $102.47 \pm 50.33$ & $99.19 \pm 63.97$ & 0.882 \\
\hline & C & $101.78 \pm 59.74$ & $102.78 \pm 58.83$ & $97.06 \pm 68.63$ & 0.882 \\
\hline \multicolumn{6}{|l|}{$\mathrm{BMD}_{\mathrm{aT} 2}(\%)$} \\
\hline & A & $121.45 \pm 53.98$ & $123.17 \pm 56.38$ & $113.39 \pm 43.53$ & 0.669 \\
\hline & B & $123.55 \pm 55.52$ & $125.93 \pm 57.82$ & $112.34 \pm 45.00$ & 0.563 \\
\hline & C & $122.74 \pm 58.81$ & $125.85 \pm 61.62$ & $108.09 \pm 43.88$ & 0.475 \\
\hline \multicolumn{6}{|l|}{$\begin{array}{l}\text { Density } \\
\text { enhancement rate } \\
(\%)\end{array}$} \\
\hline & $\mathrm{A}$ & $35.85 \pm 51.99$ & $36.37 \pm 54.51$ & $33.41 \pm 41.41$ & 0.893 \\
\hline & $\mathrm{B}$ & $35.61 \pm 51.75$ & $36.60 \pm 53.41$ & $30.94 \pm 46.47$ & 0.796 \\
\hline & C & $37.59 \pm 56.41$ & $38.25 \pm 58.38$ & $34.46 \pm 49.91$ & 0.874 \\
\hline $\begin{array}{l}\text { Pogonion } \\
\text { density }_{\mathrm{T} 1}(\mathrm{HU})\end{array}$ & & $312.86 \pm 81.68$ & $309.06 \pm 84.55$ & $330.77 \pm 69.17$ & 0.530 \\
\hline $\begin{array}{l}\text { Pogonion } \\
\text { density } 2(\mathrm{HU})\end{array}$ & & $309.60 \pm 88.60$ & $303.99 \pm 93.26$ & $336.06 \pm 60.40$ & 0.391 \\
\hline Volume $_{\mathrm{T} 1}\left(\mathrm{~mm}^{3}\right)$ & & - & $107.65 \pm 97.67$ & $77.68 \pm 47.57$ & - \\
\hline Volume $_{\mathrm{T} 2}\left(\mathrm{~mm}^{3}\right)$ & & - & $103.52 \pm 94.33$ & $72.93 \pm 31.62$ & - \\
\hline
\end{tabular}

Data are presented as means \pm standard deviations. Differences between patients with unilateral and bilateral cleft were determined using an independent $t$-test. Difference in $\mathrm{BMD}_{\mathrm{a}}$ between $\mathrm{T} 1$ and $\mathrm{T} 2$ in unilateral cases determined by a paired $t$-test: $p=0.007,0.007$, and 0.012 for Method $\mathrm{A}, \mathrm{B}$, and $\mathrm{C}$, respectively; difference in $\mathrm{BMD}_{\mathrm{a}}$ between T1 and T2 in bilateral cases determined by a Wilcoxon signed-rank test: $p=0.237,0.237$, and 0.237 for Method A, B, and C, respectively. BMD, bone mineral density; $\mathrm{BMD}_{\mathrm{a}}$, adjusted BMD.

In unilateral cases, the $\mathrm{BMD}_{\mathrm{a}}$ at $\mathrm{T} 1\left(\mathrm{BMD}_{\mathrm{aT1}}\right)$ was $100.01 \% \pm 46.98 \%, 102.47 \% \pm 50.33 \%$, and $102.78 \% \pm 58.83 \%$; the $\mathrm{BMD}_{\mathrm{a}}$ at $\mathrm{T} 2\left(\mathrm{BMD}_{\mathrm{aT} 2}\right)$ was $123.17 \% \pm 56.38 \%, 125.93 \% \pm 57.82 \%$, and $125.85 \% \pm 61.62 \%$; and the density enhancement rate was $36.37 \% \pm 54.51 \%, 36.60 \% \pm 53.41 \%$, and $38.25 \% \pm 58.38 \%$ for Method A, B, and C, respectively. No significant difference was observed for $\mathrm{BMD}_{\mathrm{aT1}}(p=0.524), \mathrm{BMD}_{\mathrm{aT2}}(p=0.572)$, or density enhancement rate $(p=0.725)$ when comparing the differences among the three methods. In bilateral cases, the $\mathrm{BMD}_{\mathrm{aT} 1}$ was $98.24 \% \pm 62.85 \%, 99.19 \% \pm 63.97 \%$, and $97.06 \% \pm 68.63 \%$; the $\mathrm{BMD}_{\text {аT2 } 2 \text { was }}$ $113.39 \% \pm 43.53 \%, 112.34 \% \pm 45.00 \%$, and $108.09 \% \pm 43.88 \%$; and the density enhancement rate was $33.41 \% \pm 41.41 \%, 30.94 \% \pm 46.47 \%$, and $34.46 \% \pm 49.91 \%$ for Method $\mathrm{A}, \mathrm{B}$, and $\mathrm{C}$, respectively. No significant difference was observed for $\mathrm{BMD}_{\mathrm{aT} 1}(p=0.066), \mathrm{BMD}_{\mathrm{aT} 2}$ $(p=1.000)$ or density enhancement rate $(p=0.66)$ when comparing the differences among the three methods.

When comparing the progressing density between $\mathrm{T} 1$ and $\mathrm{T} 2$, significant differences in $\mathrm{BMD}_{\mathrm{a}}$ were observed for the three measurement methods in unilateral cases $(p=0.007$, 0.007, and 0.012 for Method A, B, and C, respectively; Figure 5A); however, no significant differences were noted in bilateral cases $(p=0.237,0.237$, and 0.237 for Method A, B, and C, respectively; Figure 5B). 
A.

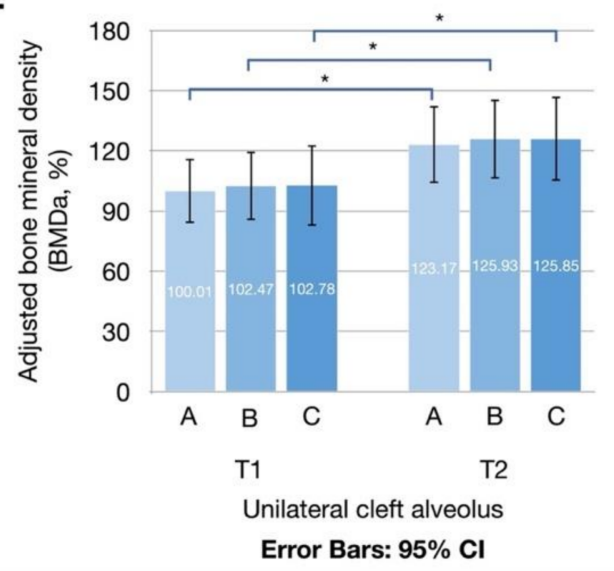

B.

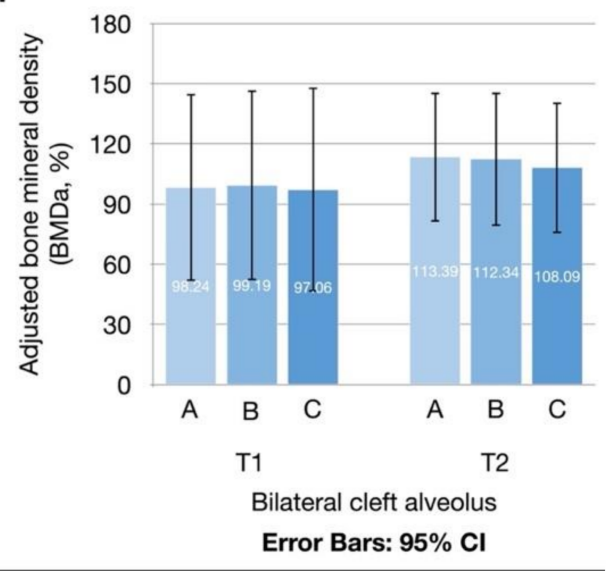

Figure 5. Error bars of adjusted bone mineral density $\left(\mathrm{BMD}_{\mathrm{a}}\right)$ of grafted tissue at $\mathrm{T} 1$ and $\mathrm{T} 2$ in individuals with $(\mathbf{A})$ unilateral alveolar cleft and (B) bilateral alveolar cleft. Significant differences among the three methods were observed in unilateral alveolar cleft $(n=33)$, but no significant differences among the three methods ( $p=0.176$ for all three methods) were observed in bilateral alveolar cleft. Stars indicate significant differences in $\mathrm{BMD}_{\mathrm{a}}$ between T1 and T2: ${ }^{*}, p<0.05$.

The volume of the grafted tissue in unilateral cases was $107.65 \mathrm{~mm}^{3} \pm 97.67 \mathrm{~mm}^{3}$ at $\mathrm{T} 1$ and $103.52 \mathrm{~mm}^{3} \pm 94.33 \mathrm{~mm}^{3}$ at $\mathrm{T} 2$; the volume of the grafted tissue in bilateral cases was $77.68 \mathrm{~mm}^{3} \pm 47.57 \mathrm{~mm}^{3}$ at T1 and $72.93 \mathrm{~mm}^{3} \pm 31.62 \mathrm{~mm}^{3}$ at T2. There was no significant difference when comparing the progressing volumetric change between $\mathrm{T} 1$ and T2 ( $p=0.781$ in unilateral cleft, and $p=0.893$ in bilateral cleft) (Table 2). Besides, the density enhancement rate of the grafted tissue did not show a significant relationship with the volume loss (Table 3).

Table 3. The correlation between volumetric loss and density enhancement rate of the grafted tissue was calculated using Spearman's correlation.

\begin{tabular}{|c|c|c|c|}
\hline & \multicolumn{3}{|c|}{ Density Enhancement Rate (\%) } \\
\hline & Method A & Method B & Method C \\
\hline \multicolumn{3}{|l|}{ Unilateral cleft alveolus } & Volume loss $(\%) *$ \\
\hline Correlation coefficient ${ }^{\circledR}$ & -0.038 & 0.019 & 0.008 \\
\hline$p$-value & 0.844 & 0.921 & 0.966 \\
\hline \multicolumn{4}{|l|}{ Bilateral cleft alveolus } \\
\hline \multicolumn{4}{|l|}{ Volume loss $(\%) *$} \\
\hline Correlation coefficient ${ }^{\circledR}$ & 0.400 & 0.400 & 0.700 \\
\hline$p$-value & 0.505 & 0.505 & 0.188 \\
\hline
\end{tabular}

\subsection{Intrarater Reliability}

Our Bland-Altman analysis verified an agreement between the two examinations performed using each method at the two follow-up time points (Figure 6). Excellent intrarater reliability (ICCs > 0.9) was noted for all measurements (Supplementary Table S1) [14]. 

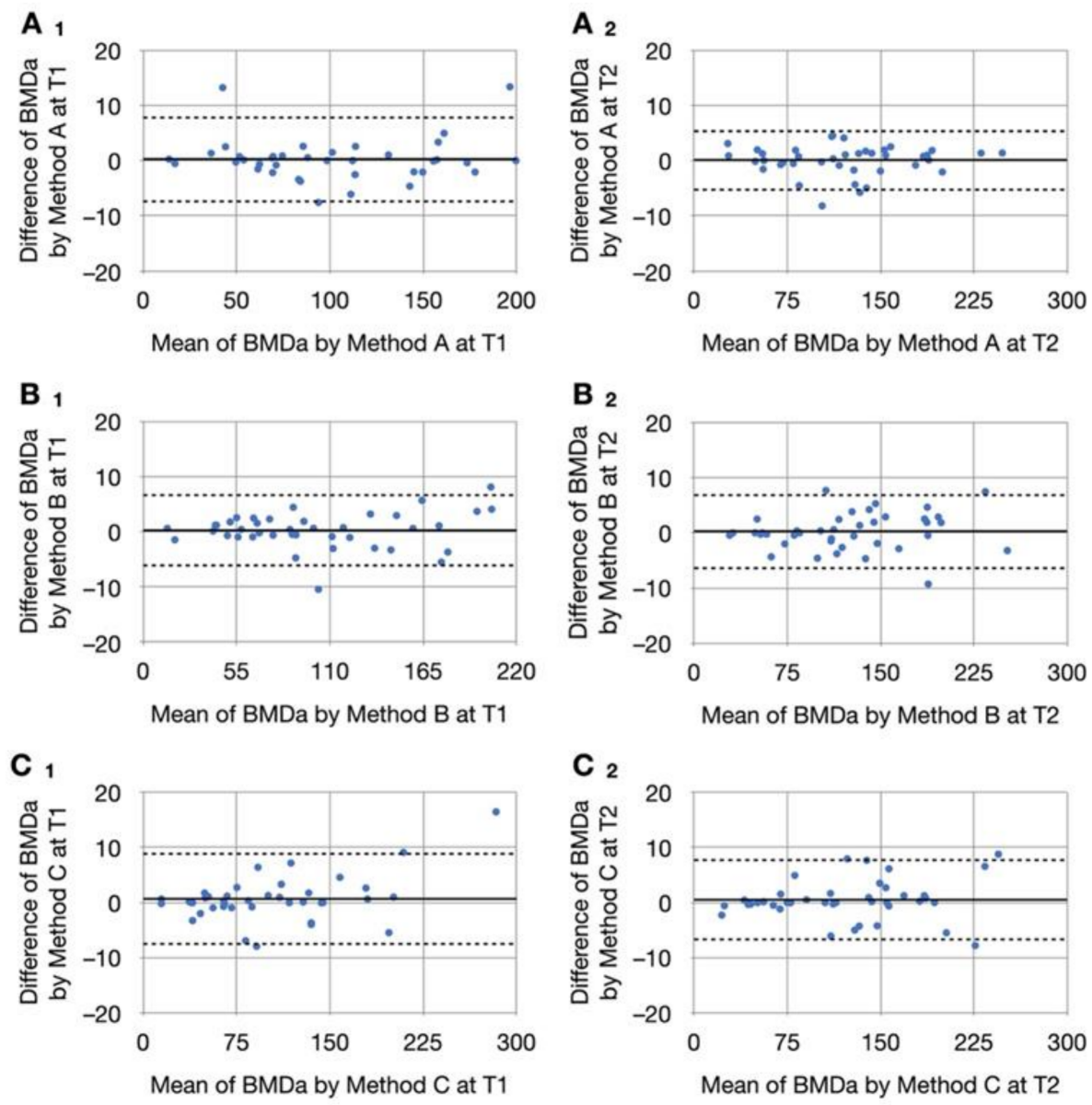

Figure 6. Distribution and consistency of results of two measurements using the same method and Bland-Altman plots. $\left(\mathbf{A}_{\mathbf{1}}\right),\left(\mathbf{B}_{1}\right)$, and $\left(\mathbf{C}_{\mathbf{1}}\right)$ plots are comparisons of two measurements conducted using Method A, B, and C, respectively, at T1; $\left(\mathbf{A}_{2}\right),\left(\mathbf{B}_{2}\right)$, and $\left(\mathbf{C}_{2}\right)$ plots are comparisons of two measurements conducted using Method A, B, and C, respectively, at T2. The mean values of differences in $\mathrm{BMD}_{\mathrm{a}}$ between two measurements of grafted tissue are approximately at and evenly distributed within the zero line, indicating that the two methods produced similar results.

\section{Discussion}

No significant differences among the three methods were observed with respect to the $\mathrm{BMD}_{\mathrm{a}}$ and density enhancement rates obtained for unilateral and bilateral alveolar cleft cases. This demonstrates that all three methods produced consistent results. However, each method still has certain advantages and disadvantages.

For Method A, the $1 \mathrm{~mm}$ gap relative to both adjacent teeth ensures that BMD measurements are not affected by the density of those teeth. Zhang et al. [11] proposed a similar method; the difference is that Method A involves the drawing of a maximum circle in the axial view, whereas the method proposed by Zhang et al. involves the drawing of six circles with a fixed size of $5 \mathrm{~mm}^{2}$ in the sagittal view. A drawback of Method A is that the surrounding cortical bone density and air density are often included in examinations of patients with large alveolar gaps. Therefore, the density of the selected area does not fully represent that of the grafted tissue.

For Method B, the selected circle contains most of the grafted area; hence, the risk of the surrounding cortical bone and air density being included is low relative to Method A. Consequently, the BMD obtained using Method B is a more objective reference. However, because the distance to the two teeth is almost tangential, but not contained, measurements must be carefully taken to avoid including sections of the teeth and therefore reducing the accuracy of the density results. 
For Method C, each selected area is fixed in size and smaller than that used in Method A; therefore, the surrounding tissue is unlikely to be included, and the density of the selected area is more consistently represented relative to the other methods. However, if the alveolar gap is too wide, the selected area will not be representative of the overall density. BMD may decrease due to osteonecrosis caused by poor peripheral blood circulation [15]; furthermore, bone density may not be evenly distributed, and in patients with large alveolar gaps the results are less representative of overall BMD relative to those obtained using the other methods.

The positive and negative aspects as well as the operating precautions of the three methods are summarized in Table 4 . Of the three methods, Method B theoretically produced the most representative density results for grafted tissue; however, our study revealed no statistical differences among the three methods. In addition, the correlation among all three methods was high (ICCs > 0.9), indicating that all three measurement methods can be applied in clinical settings.

Table 4. Comparison of the positive and negative aspects from each method.

\begin{tabular}{llll}
\hline & Method A & Method B & Method C \\
\hline Definition & $\begin{array}{l}\text { Circular zone is located } 1 \mathrm{~mm} \\
\text { from the adjacent teeth. }\end{array}$ & $\begin{array}{l}\text { The largest circular zone that } \\
\text { exactly transects the two adjacent } \\
\text { teeth or is tangent to the } \\
\text { surrounding cortical bone. }\end{array}$ & $\begin{array}{l}\text { A circle is drawn with a diameter } \\
\text { of } 2 \mathrm{~mm} .\end{array}$ \\
\hline
\end{tabular}

1. The selected circle contains most of the grafted area.

Positive aspect

BMD measurements are not affected by the density of adjacent teeth.
2. Risk of including the surrounding cortical bone and air density is low, relative to Method A.
1. Selected circle is fixed in size.

2. BMD measurements are not affected by the density of adjacent teeth.

\begin{tabular}{llll}
\hline Negative aspect & $\begin{array}{l}\text { The surrounding cortical bone } \\
\text { density and air density are } \\
\text { often included in } \\
\text { examinations of patients with } \\
\text { large alveolar gaps. }\end{array}$ & $\begin{array}{l}\text { Easily contains adjacent tooth } \\
\text { density or surrounding } \\
\text { cortical bone. }\end{array}$ & $\begin{array}{l}\text { Not representative of the overall } \\
\text { density in cases with a larger } \\
\text { alveolar gap. }\end{array}$ \\
\hline Operating precautions & - & $\begin{array}{l}\text { When measuring, care must be } \\
\text { taken of to avoid including } \\
\text { sections of the teeth. }\end{array}$ & $\begin{array}{l}\text { Ensure that the distance from the } \\
\text { circle to the two adjacent teeth is } \\
\text { equal when measuring. }\end{array}$ \\
\hline
\end{tabular}

Studies have investigated, but not validated, measurements of grafted tissue density in patients with orofacial clefts; between-method differences in BMD measurements were also observed [9,11,16-19]. Zhang et al. [11] obtained the following mean BMD measurements for grafted tissue: $406.51 \pm 71.28 \mathrm{HU}$ at 3 months postoperatively and $409.53 \pm 46.37 \mathrm{HU}$ at 6 months postoperatively. Benlidayi et al. [16] selected three sequential cross-sectional slices from the center of the corresponding area in CBCT images and obtained a BMD of $426.1 \pm 120.1 \mathrm{HU}$ with a mean follow-up period of $47.33 \pm 13.79$ months. Canan et al. [17] obtained BMD ( $273.9 \pm 175.4 \mathrm{HU}$ at 6 months postsurgery) measurements in five sequential axial planes with a height of $1 \mathrm{~mm}$ from multislice CTs. In the study of Shawky et al. [19], BMD was measured on the axial view of CTs, and the data obtained were presented as the mean of three points detected in the same axial section; these researchers obtained a mean density of $384.03 \mathrm{HU}(214.98-549.95 \mathrm{HU})$ at 6 months postsurgery. Rychlik et al. [18] calculated BMD at every tomographic layer of the grafted tissue in CTs and obtained a grafted tissue density of $352.22 \pm 84.93 \mathrm{HU}$ at 6 months after ABG.

As stated, the three methods proposed in the present study have their advantages and disadvantages. Variations in density expressed as HU may be present in CBCT images [10]; therefore, the use of $\mathrm{HU}$ to represent BMD on unadjusted CBCT images is a drawback 
of the methods proposed by Zhang et al. [11] and Benlidayi et al. [16] Moreover, when children grow older, their bone density also changes [20]. To solve the aforementioned problems, we selected the density of pogonion bone marrow as the reference for calibration, thereby ensuring that our methods and collected data would be more representative of actual density than the methods proposed in previous studies. Nasoalveolar molding (NAM) solves the problem of inconsistencies in alveolar gap approximation. In our current protocol for CLP, presurgical management with NAM was used to restrict the size of the alveolar gap [12]. However, the method proposed by Shawky et al. [19] is only suitable for cases involving large alveolar gaps. Canan et al. [17] introduced a calibration method based on cerebrospinal fluid density for grafted tissue BMD analyses; this calibration method is similar to that applied in our study. However, the changes in BMD during growth must also be considered.

Although between-study comparisons of BMD results are not meaningful, changes in BMD over time can be compared across studies. Feichtinger et al. [21] discovered that the resorption of the bone graft (which is defined by volumetric change) occurred mainly within the first year after surgery, with a mean rate of $49.5 \%$; however, a threedimensional CT-based analysis revealed a mean bone volume that was $81 \%$ of the original value at 3 years after surgery. Several studies have assessed bone resorption using bone density. Zhang et al. [11] reported that BMD remained stable between 3 and 6 months postoperatively, and Canan et al. [17] also did not detect any significant difference in BMD among the results obtained at $3(332.1 \pm 103.0 \mathrm{HU}), 6(273.9 \pm 175.4 \mathrm{HU})$, and 12 months $(263.7 \pm 183.4 \mathrm{HU})$ postoperatively.

The present study had a long follow-up period, during which the $\mathrm{BMD}_{\mathrm{a}}$ of grafted tissue at 6 months and at 2 years after ABG was compared. In our study, we calculated the volume of the grafted tissue at 6 months and 2 years after the ABG procedure, and there was no significant difference between the volume at $\mathrm{T} 1$ and $\mathrm{T} 2$, which indicated that the bone volume remained stable and the results were consistent with the current consensus. Bone resorption with volume loss was published in many studies [21-23]; however, a significant increase in the $\mathrm{BMD}_{\mathrm{a}}$ in grafted tissue was observed, and some grafted tissue $\mathrm{BMD}$ results were even higher than the pogonion BMD, which was compatible with the process of successful bone graft healing, i.e., osteoconduction, osteoinduction, and osteogenesis [24,25]. No correlation was observed between the density enhancement and the volume loss, thereby verifying that our $A B G$ method was effective and that the $B D_{a}$ of grafted tissue increased with age.

Van der Meij et al. [23] compared unilateral and bilateral groups by using CT scans to compare the transplanted bone 1 year after ABG; their results indicated that less bone remained in the bilateral group ( $45 \%$ ) relative to the unilateral group $(70 \%)$; however, no significance testing was performed due to the small sample size. In a study by Tai et al. [22], postsurgical 1-year follow-up axial and coronal CT scans revealed no significant difference in maximal bone height, coronal volume, axial volume, maximal anteroposterior width, and maximal transverse width between unilateral and bilateral groups. In our present study, the density enhancement rate was also higher in unilateral group, but no significant difference was observed, which was consistent with the current study. Furthermore, all seven children with bilateral CLP underwent one-stage ABG, indicating that even for the more difficult bilateral cleft ABG procedure (relative to the unilateral cleft ABG procedure) [26-28], the progressive consolidation of grafted tissue was not inferior to that of the unilateral group.

The present study had several limitations. First, only 40 patients were examined. A larger sample size will increase the representativeness of the results pertaining to the improved $\mathrm{BMD}_{\mathrm{a}}$ in the patients with alveolar clefts who underwent ABG surgery. Such a sample size will also allow us to better detect differences between the three methods. Second, only seven patients were diagnosed as having bilateral CLP, which limited our ability to compare unilateral and bilateral CLP results; the rarer occurrence of bilateral CLP may also explain the lack of such comparisons in the literature. Third, all patients received the same $A B G$ procedure; therefore, we could not compare the difference in 
density enhancement rates relative to other surgical procedures. Last, we used adjusted BMD (\%) in order to overcome the concern of density variations expressed as HU in CBCT images, as well as to assess the progression of BMD at different time points in cleft children; however, BMD should theoretically be the absolute value utilizing the solid phantoms, which will be improved in future studies.

We used CBCT-derived PACS as the analysis tool due to its accessibility to all surgeons; however, PACS compresses data and thus produces images of poorer quality relative to original images [29]. Furthermore, we only selected three planes as a representation of density to increase the feasibility of our proposed methods in clinical settings. In the future, 3D medical imaging software can be used to analyze images in the Digital Imaging and Communications in Medicine (i.e., DICOM) format; this allows researchers to obtain the $\mathrm{BMD}_{\mathrm{a}}$ of all grafted tissue and compare the $\mathrm{BMD}_{\mathrm{a}}$ results obtained using our proposed methods with the $\mathrm{BMD}_{\mathrm{a}}$ of the overall graft area. Finally, bone density increases when the bone matures, and these pediatric patients with CLP will undergo further orthognathic surgery (OGS) at our craniofacial center at the age of 16-20 years [12]. Therefore, with the pre-OGS CBCTs of this group [12], we can track the progressive changes in BMD between $\mathrm{ABG}$ and OGS.

\section{Conclusions}

The present study reports a significant increase in $\mathrm{BMD}_{\mathrm{a}}$ from 6 months to 2 years after $A B G$, verifying the success and feasibility of the current $A B G$ surgical protocol. We also observed that the patients' $\mathrm{BMD}_{\mathrm{a}}$ increased by time. Furthermore, we demonstrated that our three proposed methods for measuring $\mathrm{BMD}_{\mathrm{a}}$ in $\mathrm{CBCT}$ images can be applied in post-ABG evaluations.

Supplementary Materials: The following are available online at https://www.mdpi.com/article $/ 10.3390 / \mathrm{jcm} 10215143 / \mathrm{s} 1$, Table S1: Inter-rater reliability for bone mineral density (BMD) measurements of alveolar defect and pogo-nion density.

Author Contributions: Conception and design: P.-R.C. and P.-Y.C. Acquisition, analysis, and interpretation of data: P.-R.C., Y.-C.L., B.C.-J.P. and H.-J.T. Drafting the article: P.-R.C. and Y.-C.L. Critically revising the article: L.-J.L. and P.-Y.C. Reviewed submitted version of manuscript. All authors have read and agreed to the published version of the manuscript.

Funding: This work was supported in part by a grant from the Ministry of Science and Technology, Taiwan (MOST 107-2314-B-182A-117-NRRPG3H0081), and the Craniofacial Research Center, Taoyuan Chang Gung Memorial Hospital (CMRPG3J0823, CMRPG3L0361).

Institutional Review Board Statement: The study (201600968A3) was approved by the Ethics Committee for Human Research, Taoyuan Chang Gung Memorial Hospital, Taiwan.

Informed Consent Statement: Not applicable.

Data Availability Statement: The data presented in this study are available on request from the corresponding author. The data are not publicly available due to privacy.

Acknowledgments: The authors would like to thank Tanny Yi-Tan Hong for imaging data processing and the Biostatistics Unit, Clinical Trial Center, Chang Gung Memorial Hospital for statistical assistance.

Conflicts of Interest: The authors declare that the article content was composed in the absence of any commercial or financial relationships that could be construed as a potential conflict of interest.

\section{References}

1. Bajaj, A.K.; Wongworawat, A.A.; Punjabi, A. Management of alveolar clefts. J. Craniofac. Surg. 2003, 14, 840-846. [CrossRef]

2. Lonic, D.; Yamaguchi, K.; Chien-Jung Pai, B.; Lo, L.J. Reinforcing the Mucoperiosteal Pocket with the Scarpa Fascia Graft in Secondary Alveolar Bone Grafting: A Retrospective Controlled Outcome Study. Plast. Reconstr. Surg. 2017, 140, 568e-578e. [CrossRef] [PubMed]

3. Semb, G. Alveolar bone grafting. Front. Oral Biol. 2012, 16, 124-136. [CrossRef]

4. Chou, P.Y.; Denadai, R.; Hallac, R.R.; Dumrongwongsiri, S.; Hsieh, W.C.; Pai, B.C.; Lo, L.J. Comparative Volume Analysis of Alveolar Defects by 3D Simulation. J. Clin. Med. 2019, 8, 1401. [CrossRef] [PubMed] 
5. Coots, B.K. Alveolar bone grafting: Past, present, and new horizons. Semin. Plast. Surg. 2012, 26, 178-183. [CrossRef] [PubMed]

6. Han, K.; Jeong, W.; Yeo, H.; Choi, J.; Kim, J.; Son, D.; Oh, S.; Kim, C. Long-term results of secondary alveolar bone grafting using a technique to harvest pure calvarial cancellous bone: Evaluation based on plain radiography and computed tomography. J. Plast. Reconstr. Aesthet. Surg. 2017, 70, 352-359. [CrossRef] [PubMed]

7. Weissler, E.H.; Paine, K.M.; Ahmed, M.K.; Taub, P.J. Alveolar Bone Grafting and Cleft Lip and Palate: A Review. Plast. Reconstr. Surg. 2016, 138, 1287-1295. [CrossRef]

8. De Mulder, D.; Cadenas de Llano-Pérula, M.; Jacobs, R.; Verdonck, A.; Willems, G. Three-dimensional radiological evaluation of secondary alveolar bone grafting in cleft lip and palate patients: A systematic review. Dentomaxillofac. Radiol. 2018, 48, 20180047. [CrossRef]

9. Stasiak, M.; Wojtaszek-Słomińska, A.; Racka-Pilszak, B. Current methods for secondary alveolar bone grafting assessment in cleft lip and palate patients-A systematic review. J. Craniomaxillofac. Surg. 2019, 47, 578-585. [CrossRef] [PubMed]

10. Pauwels, R.; Jacobs, R.; Singer, S.R.; Mupparapu, M. CBCT-based bone quality assessment: Are Hounsfield units applicable? Dentomaxillofac. Radiol. 2015, 44, 20140238. [CrossRef]

11. Zhang, D.Z.; Xiao, W.L.; Zhou, R.; Xue, L.F.; Ma, L. Evaluation of Bone Height and Bone Mineral Density Using Cone Beam Computed Tomography After Secondary Bone Graft in Alveolar Cleft. J. Craniofac. Surg. 2015, 26, 1463-1466. [CrossRef] [PubMed]

12. Pai, B.C.J.; Hung, Y.T.; Wang, R.S.H.; Lo, L.J. Outcome of Patients with Complete Unilateral Cleft Lip and Palate: 20-Year Follow-Up of a Treatment Protocol. Plast. Reconstr. Surg. 2019, 143, 359e-367e. [CrossRef]

13. Yushkevich, P.A.; Piven, J.; Hazlett, H.C.; Smith, R.G.; Ho, S.; Gee, J.C.; Gerig, G. User-guided 3D active contour segmentation of anatomical structures: Significantly improved efficiency and reliability. Neuroimage 2006, 31, 1116-1128. [CrossRef]

14. Koo, T.K.; Li, M.Y. A Guideline of Selecting and Reporting Intraclass Correlation Coefficients for Reliability Research. J. Chiropr. Med. 2016, 15, 155-163. [CrossRef] [PubMed]

15. Pape, H.C.; Evans, A.; Kobbe, P. Autologous bone graft: Properties and techniques. J. Orthop. Trauma. 2010, 24 (Suppl. S1), S36-S40. [CrossRef] [PubMed]

16. Benlidayi, M.E.; Tatli, U.; Kurkcu, M.; Uzel, A.; Oztunc, H. Comparison of bovine-derived hydroxyapatite and autogenous bone for secondary alveolar bone grafting in patients with alveolar clefts. J. Oral Maxillofac. Surg. 2012, 70, e95-e102. [CrossRef]

17. Canan, L.W., Jr.; da Silva Freitas, R.; Alonso, N.; Tanikawa, D.Y.; Rocha, D.L.; Coelho, J.C. Human bone morphogenetic protein-2 use for maxillary reconstruction in cleft lip and palate patients. J. Craniofac. Surg. 2012, 23, 1627-1633. [CrossRef] [PubMed]

18. Rychlik, D.; Wójcicki, P. Bone graft healing in alveolar osteoplasty in patients with unilateral lip, alveolar process, and palate clefts. J. Craniofac. Surg. 2012, 23, 118-123. [CrossRef]

19. Shawky, H.; Seifeldin, S.A. Does Platelet-Rich Fibrin Enhance Bone Quality and Quantity of Alveolar Cleft Reconstruction? Cleft. Palate Craniofac. J. 2016, 53, 597-606. [CrossRef]

20. Weaver, C.M.; Gordon, C.M.; Janz, K.F.; Kalkwarf, H.J.; Lappe, J.M.; Lewis, R.; O'Karma, M.; Wallace, T.C.; Zemel, B.S. The National Osteoporosis Foundation's position statement on peak bone mass development and lifestyle factors: A systematic review and implementation recommendations. Osteoporos. Int. 2016, 27, 1281-1386. [CrossRef]

21. Feichtinger, M.; Mossböck, R.; Kärcher, H. Assessment of bone resorption after secondary alveolar bone grafting using threedimensional computed tomography: A three-year study. Cleft. Palate Craniofac. J. 2007, 44, 142-148. [CrossRef]

22. Tai, C.C.; Sutherland, I.S.; McFadden, L. Prospective analysis of secondary alveolar bone grafting using computed tomography. J. Oral Maxillofac Surg. 2000, 58, 1241-1249. [CrossRef] [PubMed]

23. Van der Meij, A.J.; Baart, J.A.; Prahl-Andersen, B.; Valk, J.; Kostense, P.J.; Tuinzing, D.B. Bone volume after secondary bone grafting in unilateral and bilateral clefts determined by computed tomography scans. Oral Surg. Oral Med. Oral Pathol. Oral Radiol. Endod. 2001, 92, 136-141. [CrossRef]

24. Lee, C.Y.; Prasad, H.S.; Suzuki, J.B.; Stover, J.D.; Rohrer, M.D. The correlation of bone mineral density and histologic data in the early grafted maxillary sinus: A preliminary report. Implant. Dent. 2011, 20, 202-214. [CrossRef] [PubMed]

25. Roberts, T.T.; Rosenbaum, A.J. Bone grafts, bone substitutes and orthobiologics: The bridge between basic science and clinical advancements in fracture healing. Organogenesis 2012, 8, 114-124. [CrossRef] [PubMed]

26. Abyholm, F.E.; Bergland, O.; Semb, G. Secondary bone grafting of alveolar clefts. A surgical/orthodontic treatment enabling a non-prosthodontic rehabilitation in cleft lip and palate patients. Scand. J. Plast. Reconstr. Surg. 1981, 15, 127-140. [CrossRef] [PubMed]

27. Collins, M.; James, D.R.; Mars, M. Alveolar bone grafting: A review of 115 patients. Eur. J. Orthod. 1998, 20, 115-120. [CrossRef] [PubMed]

28. Heidbuchel, K.L.; Kuijpers-Jagtman, A.M.; Freihofer, H.P. An orthodontic and cephalometric study on the results of the combined surgical-orthodontic approach of the protruded premaxilla in bilateral clefts. J. Craniomaxillofac. Surg. 1993, 21, 60-66. [CrossRef]

29. Khorasani, R. Image compression in your PACS: Should you do it? What are the issues? J. Am. Coll. Radiol. 2004, 1, 780-781. [CrossRef] 